\title{
Perspectives Among Canadian Physicians on Factors Influencing Implementation of Mifepristone Medical Abortion: A National Qualitative Study
}

\author{
Sarab Munro, $P b D^{1,2}$ \\ Edith Guilbert, MD, MSc ${ }^{3}$ \\ Marie-Soleil Wagner, MD, MS \\ Elizabeth S. Wilcox, $M A^{2,5}$ \\ Courtney Devane, MSN ${ }^{6}$ \\ Sheila Dunn, MD, MSc $\mathrm{C}^{7,8}$ \\ Melissa Brooks, $M D^{9}$ \\ Judith A. Soon, $R P b^{10}$ \\ Megan Mills, $M D^{11}$ \\ Genevieve Leduc-Robert, MSc ${ }^{11}$ \\ Kate Wabl ${ }^{1}$ \\ Erik Zannier, $M D^{11}$ \\ Wendy V. Norman, MD, MHSc $\mathrm{C}^{12,13}$

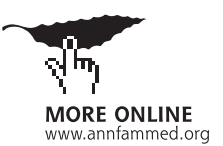

Conflicts of interest: authors report none.

\section{CORRESPONDING AUTHOR}

Wendy V. Norman

Department of Family Practice

University of British Columbia

320-5950 University Boulevard

Vancouver, BC, Canada, V6T 1Z3

wendy.norman@ubc.ca

\begin{abstract}
PURPOSE Access to family planning health services in Canada has been historically inadequate and inequitable. A potential solution appeared when Health Canada approved mifepristone, the gold standard for medical abortion, in July 2015. We sought to investigate the factors that influence successful initiation and ongoing provision of medical abortion services among Canadian health professionals and how these factors relate to abortion policies, systems, and service access throughout Canada.
\end{abstract}

METHODS We conducted 1-on-1 semistructured interviews with a national sample of abortion-providing and nonproviding physicians and health system stakeholders in Canadian health care settings. Our data collection, thematic analysis, and interpretation were guided by Diffusion of Innovation theory.

RESULTS We conducted interviews with 90 participants including rural practitioners and those with no previous abortion experience. In the course of our study, Health Canada removed mifepristone restrictions. Our results suggest that Health Canada's initial restrictions discouraged physicians from providing mifepristone and were inconsistent with provincial licensing standards, thereby limiting patient access. Once deregulated, remaining factors were primarily related to local and regional implementation processes. Participants held strong perceptions that mifepristone was the new standard of care for medical abortion in Canada and within the scope of primary care practice.

CONCLUSION Health Canada's removal of mifepristone restrictions facilitated the implementation of abortion care in the primary care setting. Our results are unique because Canada is the first country to facilitate provision of medical abortion in primary care via evidence-based deregulation of mifepristone.

Ann Fam Med 2020;18:413-421. https://doi.org/10.1370/afm.2562.

\section{INTRODUCTION}

A pproximately $40 \%$ of pregnancies in Canada are unplanned, and 1 in 3 Canadian women will have at least 1 abortion in their lifetime. ${ }^{1-4}$ Access to health services in Canada that enable patients to plan and space their pregnancies has been historically inadequate and inequitable. ${ }^{5}$ Before 2017 in Canada, abortion services were surgical and provided by fewer than 300 doctors at roughly 100 facilities in urban cities close to the Canada-US border. ${ }^{4}$ In this context, patients who lived outside large cities had to travel significant distances to access abortion care. ${ }^{6,7}$ Concern about these inequities was expressed in the November 2016 report of the Committee on Elimination of Discrimination Against Women, in which the United Nations Human Rights Commissioner called on the government of Canada to improve access. ${ }^{5}$

The approval of mifepristone medical abortion in July 2015 by Health Canada (the equivalent of the US Food and Drug Administration) appeared to be a potential solution to improve abortion access in the primary care setting. ${ }^{8-10}$ Mifepristone became available for prescription 
by physicians in January 2017. Mifepristone is on the World Health Organization's list of essential medicines ${ }^{11}$ and is considered the gold standard for medical abortion. ${ }^{8}$ Mifepristone $200 \mathrm{mg}$ oral and misoprostol $800 \mathrm{mg} \mathrm{buccal} / \mathrm{vaginal} / \mathrm{sublingual}$ is the regimen of choice for medical abortion up to 70 days after the last menstrual period among eligible women. ${ }^{1}$ Data on use of mifepristone in other nations since 1988 suggests that the drug is associated with an increased proportion of medical abortion compared with surgical abortion but not with an increase in overall abortion rates. ${ }^{12}$ Health Canada's approval of mifepristone ${ }^{9}$ included restrictions, such as mandated physician dispensing and registration with the manufacturer, that have contributed to a low uptake of mifepristone in primary care in similar high-income nations including the United States. ${ }^{10,12-15}$

We hypothesized that Health Canada's restrictions would impede implementation of mifepristone in primary care. ${ }^{16}$ We also anticipated that stakeholderreported barriers and facilitators to implementation could inform improvements to Canadian abortion policy and practice. The present study was part of a larger mixed-methods investigation. ${ }^{17}$ In the main study, we asked the following questions: What are the factors that influence successful initiation and ongoing provision of medical abortion services among health professionals, and how do these relate to health policies, systems, and services, and to abortion service access throughout Canada? The present study focused on the first question involving the identification of factors that influence the initiation and provision of medical abortion from the perspectives of Canadian physicians and stakeholders. This research is a particularly novel contribution

\section{Table 1. Changes to Health Canada Regulations for Mifepristone- Misoprostol Medical Abortion, as of January 2020}

\begin{tabular}{|c|c|c|}
\hline Topic & Change & Date Changed \\
\hline $\begin{array}{l}\text { Observed } \\
\text { ingestion }\end{array}$ & $\begin{array}{l}\text { Removed requirement for observation of mifepris- } \\
\text { tone ingestion. The patient can take the drug } \\
\text { where and when they choose. }\end{array}$ & October 2016 \\
\hline Training & Removed requirement for training for pharmacists. & May 2017 \\
\hline Training & Removed requirement for training for prescribers. & November 2017 \\
\hline Consent form & $\begin{array}{l}\text { Removed requirement for a manufacturer consent } \\
\text { form to be signed by the patient. }\end{array}$ & November 2017 \\
\hline Registration & $\begin{array}{l}\text { Removed requirement for registration of prescrib- } \\
\text { ers or pharmacists with the manufacturer. }\end{array}$ & November 2017 \\
\hline Dispensing & $\begin{array}{l}\text { Mifepristone can be dispensed directly to patients } \\
\text { by a pharmacist or prescribing health profes- } \\
\text { sional, rather than the original requirement that } \\
\text { a physician must dispense directly to the patient. }\end{array}$ & November 2017 \\
\hline $\begin{array}{l}\text { Gestational } \\
\text { age }\end{array}$ & $\begin{array}{l}\text { Mifepristone-misoprostol may be used up to } 9 \\
\text { weeks ( } 63 \text { days) from the last menstrual period, } \\
\text { rather than the original } 7 \text { weeks ( } 49 \text { days). }\end{array}$ & November 2017 \\
\hline Ultrasound & $\begin{array}{l}\text { Removed requirement for mandatory ultrasound } \\
\text { before prescribing. }\end{array}$ & April 2019 \\
\hline
\end{tabular}

to the literature given that Health Canada repealed its initial restrictions on mifepristone in real time over the course the study-in October 2016, May 2017, November 2017, and April 2019 (Table 1). These changes made it possible to prescribe and dispense mifepristone in the same way as most other drugs in Canada. This study will be relevant to other nations experiencing challenges with access to family planning services given that Canada is the first to use evidence-based deregulation of mifepristone to facilitate provision of medical abortion in the primary care setting.

\section{METHODS}

\section{Study Design}

This national interview study aimed to explore factors that influence implementation of mifepristone medical abortion in Canadian health service delivery and health systems. Our approach was guided by Rogers' theory of the Diffusion of Innovations, ${ }_{1}^{18}$ as articulated by Greenhalgh and colleagues ${ }^{19}$ and Cook and colleagues. ${ }^{20}$ Our qualitative study was a component of a national, 4-year, prospective, mixed-methods, observational program of research on factors that influence the implementation of mifepristone use in primary care, the Contraception and Abortion Research Team-Mifepristone (CARTMife) Study. A fulsome account of our methods and integrated knowledge translation ${ }^{21}$ approach for the entire study can be found in our research protocol. ${ }^{17}$ Our survey data collection is ongoing and not reported in the present study. Our approach was guided by the Standards for Reporting Implementation Studies statement. ${ }^{22}$ Ethical approval was provided by the Behavioral Research Ethics Board of the University of British Columbia and BC Women's and Children's Hospital.

\section{Setting}

Our study took place in the context of Canadian health care settings, which we defined as any service delivery environment where a prescriber could provide primary care, including hospitals, abortion facilities, health centers, and private physician offices, as well as via telemedicine.

\section{Participants}

Following Greenhalgh's guidance, ${ }^{19}$ we sought to interview potential adopters and representatives of organizations that had an interest or concern in implementation of mifepristone use. Individuals eligible to participate in interviews 
included physicians who intended to begin practice with mifepristone within the first year of availability; health care professionals, such as family physicians, who were eligible to become mifepristone prescribers but did not pursue this practice; and stakeholders (eg, representatives of Health Canada, health care professional colleges, and advocacy groups) who had the potential to affect health policy, system, and service factors that influence implementation of mifepristone. Participants had to be English or French speaking and reside in Canada at the time of the interview to participate.

\section{Recruitment}

For physicians who intended to begin practice with mifepristone within the first year of availability, we invited those who completed a CART-Mife Study national online survey during the period January to December 2017 and responded that they would like to participate to participate in an interview. All interview invitations and a copy of the consent form were sent by e-mail to potential participants. We invited nonproviding health care professionals and stakeholders via third-party recruitment with the assistance of the study's knowledge user partners (eg, health professional organizations). We also asked each nonproviding physician if they would refer potential participants to the study (snowball recruitment). The potential study population was purposefully sampled to represent diversity of demographic characteristics (eg, sex, age, profession, region) and factors related to the implementation of mifepristone (eg, previous abortion practice).

Sampling, data collection, and analysis were iterative rather than linear steps to collect sufficient data to illustrate the phenomenon of mifepristone implementation in Canada. As categories emerged from analysis of transcripts, we engaged in theoretical sampling that guided our invitation of physicians to participate in a repeat interview 12 months later. Sampling for repeat interviews was guided by the following question:

Given our emerging understanding of the factors that influence implementation, which participants would provide the most useful data to further develop those concepts? We invited physicians who were likely to have information-rich cases of adoption or nonadoption to repeat interviews. We also used stratified, purposeful sampling (per above) to ensure that repeat interview participants remained diverse and had varying experiences of abortion practice in the year following mifepristone availability. ${ }^{23}$

\section{Data Collection}

We developed and pilot-tested our interview guide with a panel of researchers and clinicians before data collection (Supplemental Appendix 1, https://www. AnnFamMed.org/content/18/5/413/suppl/DC1/). Oneon-one semistructured interviews were conducted by telephone in the first year of mifepristone availability at least 3 months after participants had completed training (April to December 2017). Repeat interviews were conducted 1 year later (October to December 2018). Three health services researchers (S.M., E.G., M-S.W.) conducted the interviews with support from a team of trainees from nursing, medicine, and population and public health (C.D., M.M., G.L-R., K.W., E.S.W., E.Z.). The trainees completed a full-day training workshop on the study procedures before engaging in data collection. During interviews, we sought to be attuned to the participants' comfort level and differences in power and status. Data collection and analysis were concurrent. We conducted interviews until we achieved saturation, when new data repeated what was in previous data (in our data collection), themes were well exemplified in participant data (in our sampling), and no new themes emerged (in our analysis). ${ }^{24,25}$ We also sought to recruit participants until the data sufficiently represented a range of the preidentified factors from the purposeful sampling strategies. To ensure transparency and rigor, we engaged in verification strategies throughout, including constant comparison, keeping an audit trail, and sampling to theoretical sufficiency. All interviews were audio-recorded.

\section{Data Analysis}

Interviews were transcribed and French interviews were translated to English before 2 qualitative researchers (S.M., E.S.W.) subjected the data to thematic analysis, informed by Braun and Clarke's flexible approach. ${ }^{26}$ Each participant was assigned a unique identifier (eg, 011_Phys - family physician, rural British Columbia, previous medical and surgical abortion experience). We deidentified and coded a sample of transcripts independently and compared results. Discrepancies were resolved via discussion with a third team member (W.V.N. or E.G.). We developed a codebook inductively by identifying codes (themes) from the transcripts that were related to the research objectives and then mapped the themes to constructs in Diffusion of Innovation theory. We then explored individual, organizational, and system patterns, relationships, and interactions between the codes. To explain physicians' implementation behavior, we considered the prevalence of themes across the data, the presence of conflicting themes, and the perceived relevance of the themes. Finally, we wrote the analysis into a descriptive, explanatory narrative that illuminated the factors influencing implementation of mifepristone abortion practice. 


\section{RESULTS}

We conducted 1-on-1 interviews with health care professionals $(\mathrm{n}=55)$ and stakeholders $(\mathrm{n}=35)$ involved in the planning and provision of abortion services in Canada (Table 2). We conducted repeat interviews with 27 of the 55 health care professionals at least 12

\section{Table 2. Participant Characteristics}

\begin{tabular}{|c|c|}
\hline Characteristic & No. \\
\hline \multicolumn{2}{|l|}{ Profession } \\
\hline Family physician/general practice & 45 \\
\hline Gynecologist & 8 \\
\hline Other primary health care professionala & 2 \\
\hline \multicolumn{2}{|l|}{ Stakeholder } \\
\hline College or regulatory body & 13 \\
\hline Advocate or advocacy group & 9 \\
\hline Government & 7 \\
\hline Abortion facility & 6 \\
\hline Total of profession and stakeholder & 90 \\
\hline \multicolumn{2}{|l|}{ Region $^{b}$} \\
\hline National & 9 \\
\hline British Columbia & 19 \\
\hline Prairies (Alberta, Saskatchewan, Manitoba) & 14 \\
\hline Ontario & 14 \\
\hline Quebec & 20 \\
\hline Atlantic (New Brunswick, Nova Scotia, Newfoundland) & 9 \\
\hline Territories (Yukon, Northwest Territories, Nunavut) & 5 \\
\hline Total & 90 \\
\hline \multicolumn{2}{|l|}{ Sex (self-reported) } \\
\hline Female & 68 \\
\hline Male & 20 \\
\hline Other/did not respond & 2 \\
\hline Total & 90 \\
\hline \multicolumn{2}{|l|}{ Health care professional age, $y$} \\
\hline $20-29$ & 5 \\
\hline $30-39$ & 25 \\
\hline $40-49$ & 11 \\
\hline $50-59$ & 10 \\
\hline $60-69$ & 4 \\
\hline Total & 55 \\
\hline \multicolumn{2}{|l|}{ Health care professional practice location } \\
\hline Urban & 33 \\
\hline Rural & 22 \\
\hline Total & 55 \\
\hline \multicolumn{2}{|l|}{$\begin{array}{l}\text { Health care professional abortion experience at time of } \\
\text { study enrollment }\end{array}$} \\
\hline Surgical only & 9 \\
\hline Medical only & 5 \\
\hline Surgical and medical & 24 \\
\hline None & 17 \\
\hline Total & 55 \\
\hline \multicolumn{2}{|c|}{$\begin{array}{l}\text { a Other primary health care professional (eg, nurse practitioner, emergency } \\
\text { medicine). } \\
\text { b Participants reported collectively from some provinces and territories to pro- } \\
\text { tect anonymity due to small numbers. }\end{array}$} \\
\hline
\end{tabular}

months after their initial interview to explore experiences of mifepristone provision. All 90 participants were volunteers, and all who consented to participate completed their interview. Among those who had provided abortions before mifepristone's availability, their experiences were diverse and ranged from writing 1 prescription for methotrexate-misoprostol to full-time surgical abortion practice.

Participants' perceptions of barriers and facilitators to implementation of mifepristone in routine primary care involved 4 overarching themes informed by Diffusion of Innovation theory as follows: (1) federal restrictions made mifepristone more complicated than it needs to be ${ }_{i}(2)$ navigating the huge bureaucratic

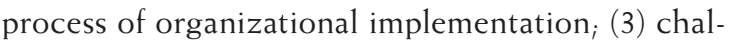
lenges with diffusion and dissemination of policy information; and (4) adoption by individuals was a process rather than an event. Themes and representative quotations are provided in Supplemental Appendix 2, https://www.AnnFamMed.org/content/18/5/413/ suppl/DC1/.

\section{Health Canada Made Mifepristone More Complicated Than it Needs to Be}

Participants' interviews illuminated how Health Canada's initial restrictions influenced their ability to implement mifepristone in routine care. In the first year of mifepristone availability (2017), all of Health Canada's regulations for the distribution of mifepristone were perceived to create unfeasible task issues that limited adoption of mifepristone abortion and in turn limited equitable access. Whereas participants valued the knowledge from the online training modules, they also perceived training to be time-consuming and the registration with the manufacturer to be a breach of their privacy. Participants hypothesized that these factors would discourage other physicians from practice and thereby limit women's access to medical abortion (006_Phys - family physician, Territories, previous medical and surgical abortion experience).

New prescribers with limited abortion experience emphasized that the initial requirement for physicianonly dispensing of mifepristone was inconsistent with their scope of practice and that in their experience dispensing was the responsibility of pharmacists. One noted, "I would definitely not have done this had they stuck to the original rules where we had to purchase, store all the products" (011_Phys - family physician, rural British Columbia, previous medical and surgical abortion experience). The requirement for ultrasound to be used for gestational age dating and to rule out ectopic pregnancy limited the ability of clinicians to provide mifepristone in areas where they felt their local access to timely ultrasound was challenging. In 
contrast, those working in established abortion facilities perceived it to be an easy transition to prescribe mifepristone, owing to existing infrastructure, billing mechanisms, and skilled counselors.

Participants were unanimous in their criticism of an initial requirement that mifepristone be a directly observed dosing, as one participant clarified, "I can't think of a safety reason that is more significant for that medication than it is for tons of other things that are prescribed and taken at or from a pharmacy" (013_Phys - family physician, urban British Columbia, no previous abortion experience). This restriction was perceived as a paternalistic barrier to patient access rather than a factor directly influencing clinician uptake. Although it remained in the product monograph initially, Health Canada removed this restriction before mifepristone became available in January $2017 .{ }^{27}$ Despite this early policy change before the start of the present study, a number of participants misbelieved that they had to observe their patients take the drug.

\section{Navigating the Huge Bureaucratic Process of Organizational Implementation}

The majority of Health Canada's federal restrictions were removed within the first year of availability (January-November 2017). Participants perceived that the deregulated mifepristone regimen was simple and compatible with their primary care practice. However, participants described persistent organizational barriers to implementing mifepristone in their local setting. Funding was a key challenge and included provincial variation in patient subsidies for the cost of the drug and in physician billing codes. Unequal costs and compensation across Canada created what participants described as a 2-tiered system, in which patients had financial access to surgical and medical options in one province, but in another they could face out-ofpocket charges only for medical abortion. Physicians described encountering a huge bureaucratic process, such as adding the billing code for medical abortion to their payment system, before they could begin to prescribe mifepristone (003_Phys - family physician, urban Ontario, previous medical and surgical abortion experience).

Conscientious objection and antichoice attitudes in organizations actively prevented physicians from implementing mifepristone abortion. Participants described hospital staff who refused to clean clinic rooms where abortion care was provided, hospital administrators who ignored requests to implement a medical abortion protocol, and community pharmacists who refused to dispense mifepristone. These attitudes contributed to geographic variation in the implementation of mifepristone.
Experiences of stigma and harassment from the general public were uncommon: "It's not like we have people demonstrating outside the hospital or clinic about abortions. It's not to that degree. It's more just the obstruction caused by people's personal views" (040_Phys - family physician, rural British Columbia, previous medical abortion experience). Whereas this did not affect participants' willingness to implement mifepristone, it did influence how much they were willing to communicate or advertise their services as an abortion provider. To avoid scrutiny, some physicians chose to "do it kind of in the dark" and not to disclose their practice to family, friends, or colleagues (004_ Phys - family physician, urban Ontario, no previous abortion experience).

Whereas universal coverage for mifepristone was established in Quebec during the first year of mifepristone's availability in Canada, a separate policy process contributed an additional year of delay in making it available in that province. In addition, the Quebec College of Physicians added its own restriction requiring accredited training in surgical abortion for any mifepristone provider. Some participants felt that Quebec professional colleges were being unnecessarily restrictive (022_Stakeholder - national advocate), and others reflected that Quebec's challenges might have been mitigated if Health Canada had collaborated early on with provincial colleges to understand how regulations differed across provinces and territories (E8_Stakeholder and E9_Stakeholder - Quebec college/regulatory body decision makers).

Participants reflected positively on the examples set by British Columbia and Ontario, provinces where professional colleges of pharmacy and medicine chose to overrule Health Canada's restrictions soon after mifepristone's approval and to allow pharmacists to dispense directly to patients. Participants perceived that the actions in British Columbia and Ontario increased access and safety by supporting "doctors [to] do what they want using their own best medical discretion" (022_Stakeholder - national advocate). Participants described how such actions emboldened health professional regulators in other provinces to follow suit and ease restrictions on mifepristone dispensing.

In rural communities, prescribers spoke about the realities of caring for patients who were distributed across vast geographic catchments and faced overwhelming barriers to access all primary care services, not just abortion. Some participants felt that it would be more feasible and private for many rural patients to access a single surgical abortion appointment compared with the multiple visits required for mifepristone medical abortion. Concerns about loss to follow-up for postabortion care were strong for some 
participants. As one participant reflected, surgical abortion "is more certain. They make one trip to the city. It's a done deal. They go home. They don't have to follow up" (002_Stakeholder - advocate, Prairie province). Participants who were not concerned about potential complications said that having a sounding board of support from expert colleagues helped to assuage their fears.

Despite these implementation barriers at the organizational level, prescribers felt that the tasks involved in providing mifepristone were relatively simple, compatible with their practice, and easy to learn through self-study. For example, one prescriber who had never provided abortion was surprised at how straightforward it was and recalled thinking, "That was so crazy easy" (034_Phys - rural family physician, Atlantic province, no previous abortion experience).

\section{Challenges With Diffusion and Dissemination of Policy Information}

During the first year of availability, as Health Canada removed restrictions, participants struggled to make sense of rapidly changing and inconsistent information about the shifting regulations:

"It seems almost every week there's a new announcement about some kind of change in funding or regulation or all this sort of stuff that makes it very difficult as a provider to know what you can and can't do. I actually think I don't know why it has been rolled out this way, but I think it's been made way more complicated than it needs to be." (017_Phys - family physician, urban Ontario, previous medical and surgical abortion experience)

Participants described how a regulatory change would be reported in the news media, but the product monograph would remain unchanged on existing stock. As one physician from urban Ontario reflected in the summer of the first year of mifepristone availability, "Is the pharmacist supposed to observe them taking the medication? Am I supposed to have the medication delivered to my office and then the patient come back? I don't actually, really, understand what the rule is there" (022_Phys - family physician, urban Ontario, previous medical abortion experience). Having peers on hand to act as a sounding board was critical, particularly for rural prescribers (040_Phys - family physician, rural British Columbia, previous medical abortion experience). This confusion was still present in repeat interviews conducted with participants in the year after mifepristone was deregulated.

Participants who were members of the community of practice component of our main study, the Canadian Abortion Providers Support (CAPS) platform, ${ }^{28}$ consistently cited the platform's biweekly emails as a reliable source of information on changing regulations. Nonetheless, participants expressed a need for more public communication about mifepristone as a new standard of care for family physicians to raise awareness among both practitioners and the public. These attitudes often were intertwined with the belief that these practitioners had a responsibility to support access to reproductive care (012_Stakeholder - advocate, Prairies).

\section{Adoption by Individuals: A Process Rather Than an Event}

According to Diffusion of Innovation theory, "adoption is a process rather than an event, with different concerns being dominant at different stages." ${ }^{\prime 19}$ Factors related to individual physician behavior, such as ability, skills, and motivation, influenced implementation of mifepristone in routine care. Preadoption, physicians first had to be aware of mifepristone, have up-to-date information about Health Canada's changes, and have a clear perspective of how it would benefit their practice and patient population. During early use, participants' confidence in prescribing mifepristone increased as they honed their skills and knowledge with each successful abortion. One described how this in turn led to increasing the percentage of medical vs surgical abortions at their clinic:

"Well, [the benefit] is already apparent to us. We have seen it on 250 patients thus far. That is more than we would see in an entire year when we were using methotrexate... Just seeing that, for those of us who have been around for as long as I have, it is a bit jaw dropping how well it works. It makes me even angrier that it took this long to get, that women were denied this for so long." (003_Stakeholder - facility leader, Prairie province)

One key facilitator was participants' perceptions of the relative advantage of mifepristone in comparison to methotrexate medical abortion. They perceived that mifepristone was a more effective, reliable, and safe treatment. It also was seen to enhance access by allowing patients to manage an abortion in their own home at their convenience (019_Stakeholder - advocate, British Columbia) and via primary care: "I think it puts access into family doctors' hands because it's a lot more within our realm than going on and doing training in surgical abortions" (004_Phys- family physician, urban Ontario, no previous abortion experience). Our repeat interviews with participants suggested providing even 1 medical abortion strengthened these attitudes.

Participants viewed mifepristone as the new best practice for medical abortion in Canada, which was a motivator to start providing it. As one family physician reflected, "Like I said, it's the standard of care for the 
physicians" (038_Phys - family physician, rural British Columbia, no previous abortion experience). Our repeat interviews indicated that many family physicians in the sample became motivated to provide mifepristone after getting a well-timed nudge, such as counseling a patient with an unplanned pregnancy or hearing a colleague's experience of prescribing it. A sample of urban physicians who did not yet prescribe mifepristone, however, expressed that they were experiencing "inertia" (042_Phys - family physician, urban British Columbia, previous medical abortion experience) and would prefer the convenience of continuing to refer their patients to nearby abortion clinics. For these nonprescribers, the key preadoption barrier was a perception that abortion was already accessible in their urban community.

\section{DISCUSSION}

\section{Main Findings}

We undertook a national qualitative investigation of physicians' and stakeholders' perceptions of the factors influencing implementation of mifepristone medical abortion during its first 2 years of availability in Canada. Our results indicate that uptake was initially challenging, owing to restrictions contained in the federal approval of mifepristone; however, within the first year of availability (January-November 2017) these restrictions were removed, and mifepristone could be prescribed in primary care settings and dispensed in pharmacies (Table 1). Despite the deregulation of mifepristone at the federal level, a number of barriers persisted throughout the study period at the organizational and individual levels, which made it difficult to implement mifepristone in primary care. These barriers included provincial variation in patient subsidies and physician billing codes, provincial restrictions from the Quebec College of Physicians, and lack of motivation to provide mifepristone among some family physicians who assumed that abortion was already accessible in their communities. Ongoing implementation of mifepristone will require Canadian organizations to create tailored solutions to these local barriers, which might include creating new billing codes, provincial policy advocacy efforts in Quebec, and conducting physician engagement to increase awareness of access barriers. Reflecting the variation in regulations between provinces, perceptions of barriers were lower in British Columbia, Ontario, and Alberta, and higher in Quebec, where availability was further delayed. Despite these barriers, participants held strong perceptions that mifepristone was the new standard of care for medical abortion in Canada and within the scope of primary care practice.

\section{Interpretation}

Our results are consistent with research in highincome nations, which documents that federal regulations are barriers to the uptake of mifepristone. ${ }^{12,29,30}$ Participants in our study who did not intend to engage in medical abortion expressed a sense of inertia similar to that reported by Australian general practitioners who perceived that abortion is a service provided in specialist clinics and that abortion will draw unwanted stigma. ${ }^{31}$ Our results suggest that providers might incorrectly perceive medical abortion risks to be greater than those related to continued pregnancy, despite strong evidence to the contrary. ${ }^{1,32-34}$ Loss to follow-up might occur for $10 \%$ to $20 \%$ of medical abortion cases. ${ }^{35}$ International studies, however, have shown that severe complications are rare. ${ }^{1,36}$

Our research might have important implications for the United States, where a number of the restrictions that Health Canada repealed are still mandated nationwide. The US Risk Evaluation and Mitigation Strategy for mifepristone includes elements to ensure safe use of the drug as follows: pharmacists cannot dispense directly to patients, prescribers must be registered with the drug distributor, and patients must sign a mandated agreement form. ${ }^{14}$ Our results indicate that Canadian physicians perceived that these elements would not enhance safety, would discourage other physicians from practice, and would limit access to abortion. The experience of implementing mifepristone in the absence of regulations will be relevant for jurisdictions such as the United States and might be useful in efforts to bring the drug label in line with current international practice and evidence. . $^{37,38}$

\section{Strengths and Limitations}

Our results will have relevance for other high-income nations where medical abortion is provided in the primary care setting. Canada's experience illustrates how evidence-based deregulation of mifepristone might facilitate its provision and increase access. Strengths of our study are the national sample, interviews conducted at 2 time points, and inclusion of new and experienced abortion providers, physicians not involved in abortion services, and stakeholders responsible for rural and urban family planning services. These stakeholders are ideally positioned to reflect on the factors that influence uptake of medical abortion at the individual, organizational, and system levels. An additional strength of this national sample is the inclusion of experiences of practitioners from regions with historically limited abortion access including the Territories and Atlantic provinces. Our results might be limited by including only 1 nurse practitioner in the sample, who became eligible to provide medical abortion during the 
study. In future research, our team will explore their perspectives, as well as those of midwives, patients, and pharmacists. We investigated mifepristone implementation in its early phase, during which Health Canada made significant changes to the regulation of this drug As use and familiarity with mifepristone increase, the barriers and facilitators will likely change.

\section{Conclusion}

In the first 2 years since mifepristone has been made available in Canada, rapid regulatory revisions greatly assisted primary care practitioners to implement abortion care, particularly in rural communities. These changes have led to health care professional perceptions that there are minimal regulatory barriers to medical abortion practice. Our results are unique internationally given that Canada is the first nation to facilitate provision of medical abortion in the primary care setting via evidence-based deregulation of mifepristone. To read or post commentaries in response to this article, see it
online at https://www.AnnFamMed.org/content/18/5/413.

Key words: abortion; family planning; health policy; health services accessibility; implementation; qualitative research; interview

Submitted August 30, 2019; submitted, revised, January 21, 2020; accepted February 11, 2020.

Author affiliations: Department of Obstetrics and Gynaecology, University of British Columbia, Vancouver, British Columbia, Canada (S.M., K.W.); Centre for Health Evaluation and Outcome Sciences, Providence Health Care Research Institute, Vancouver, British Columbia, Canada (S.M, E.S.W.); Department of Obstetrics and Gynaecology, Laval University, Quebec City, Quebec, Canada (E.G.); Department of Obstetrics and Gynaecology, University of Montreal, Montreal, Quebec, Canada (M.W.); School of Population and Public Health, University of British Columbia, Vancouver, British Columbia, Canada (E.S.W.); School of Nursing, University of British Columbia, Vancouver, British Columbia, Canada (C.D.); Department of Family and Community Medicine, University of Toronto, Toronto, Ontario, Canada (S.D.); Women's College Research Institute, Toronto, Ontario, Canada (S.D.); Department of Obstetrics and Gynaecology, Dalhousie University, Halifax, Nova Scotia, Canada (M.B.); Faculty of Pharmaceutical Sciences, University of British Columbia, Vancouver, British Columbia, Canada (J.A.S.); Faculty of Medicine, University of British Columbia, Vancouver, British Columbia, Canada (M.M., G.L., E.Z); Department of Family Practice, University of British Columbia, Vancouver, British Columbia, Canada (W.V.N.); Faculty of Public Health and Policy, London School of Hygiene \& Tropical Medicine, London, United Kingdom (W.V.N.).

Funding support: Canadian Institutes of Health Research (PHE148161, (PP-329455-107837); Michael Smith Foundation for Health Research (Award 16743, 16603, 2012-5139 [HSR]); Society of Family Planning (SFPRF11-19). S.M. was supported as a Trainee and a Scholar of the Michael Smith Foundation for Health Research (16603, 18270). W.V.N. was supported as a Scholar of the Michael Smith Foundation for Health Research (2012-5139 [HSR]) and as an Applied Public Health Research Chair by the Canadian Institutes of Health Research (CPP-329455107837). In-kind support was contributed by the Society of Obstetricians and Gynaecologists of Canada (SOGC), the College of Family Physicians of Canada, the Canadian Pharmacists Association, and the
Women's Health Research Institute of British Columbia Women's Hospital and Health Centre of the Provincial Health Services Authority of British Columbia. The SOGC supported development and design of the Community of Practice Platform that contributed to participant recruitment and retention via a contract with the last author's institution. All grants underwent external peer review for scientific quality, and the funders played no role in conducting the research or writing the paper.

Acknowledgments: Thank you to past and present members of the CART-Mife Implementation Study team for providing expert and professional feedback in preparing this study: Stirling Bryan, Janusz Kaczorowski, Tamil Kendall, Eleni Stroulia, Flora Teng, Ashley Waddington, Glenys Webster. Our thanks to Marianne Manuge for translation of interviews from French to English.

Supplementary materials: Available at https://www.AnnFam Med.org/content/18/5/413/suppl/DC1/.

\section{References}

1. Costescu D, Guilbert E, Bernardin J, et al; Society of Obstetricians and Gynecologists of Canada. Medical abortion. J Obstet Gynaecol Can. 2016;38(4):366-389.

2. Black A, Guilbert E, Costescu D, et al; Society of Obstetricians and Gynaecologists of Canada. Canadian Contraception Consensus (Part 1 of 4). J Obstet Gynaecol Can. 2015;37(10):936-942.

3. Norman WV. Induced abortion in Canada 1974-2005: trends over the first generation with legal access. Contraception. 2012;85(2): 185-191.

4. Norman WV, Guilbert ER, Okpaleke C, et al. Abortion health services in Canada: results of a 2012 national survey. Can Fam Physician. 2016;62(4):e209-e217.

5. United Nations Convention on the Elimination of All Forms of Discrimination Against Women. Concluding observations on the combined 8th and 9th periodic reports of Canada: Committee on the Elimination of Discrimination against Women. https://digitallibrary. un.org/record/3802136? In =en. Published Nov 25, 2016. Accessed Jul 27, 2020.

6. Sethna C, Doull M. Spatial disparities and travel to freestanding abortion clinics in Canada. Womens Studies International Forum. 2013;38:52-62.

7. Sethna C, Doull M. Far from home? A pilot study tracking women's journeys to a Canadian abortion clinic. J Obstet Gynaecol Can. 2007; 29(8):640-647.

8. Dunn S, Cook R. Medical abortion in Canada: behind the times. CMAJ. 2014;186(1):13-14.

9. Government of Canada. Regulatory Decision Summary - Mifegymiso - Health Canada. https://www.hc-sc.gc.ca/. Published 2015. Accessed Jul 27, 2020.

10. Newton D, Bayly C, McNamee K, et al. '....a one stop shop in their own community': medical abortion and the role of general practice. Aust N Z J Obstet Gynaecol. 2016;56(6):648-654.

11. World Health Organization. WHO model lists of essential medicines. https://www.who.int/medicines/publications/essentialmedicines/en/. Published 2005. Accessed Jul 27, 2020.

12. Jones RK, Henshaw SK. Mifepristone for early medical abortion: experiences in France, Great Britain and Sweden. Perspect Sex Reprod Health. 2002;34(3):154-161.

13. Templeton A, Grimes DA. Clinical practice. A request for abortion. N Engl J Med. 2011;365(23):2198-2204.

14. Raymond EG, Blanchard K, Blumenthal PD, et al; Mifeprex REMS Study Group. Sixteen years of overregulation: time to unburden mifeprex. N Engl J Med. 2017;376(8):790-794.

15. Baird B. Medical abortion in Australia: a short history. Reprod Health Matters. 2015;23(46):169-176. 
16. Norman WV, Soon JA. Requiring physicians to dispense mifepristone: an unnecessary limit on safety and access to medical abortion. CMAJ. 2016;188(17-18):E429-E430.

17. Norman WV, Munro S, Brooks M, et al. Could implementation of mifepristone address Canada's urban-rural abortion access disparity: a mixed-methods implementation study protocol. BMJ Open. 2019;9(4):e028443.

18. Rogers EM. Diffusion of Innovations. 5th ed. New York, NY: Simon \& Schuster; 2003.

19. Greenhalgh T, Robert G, Macfarlane F, Bate P, Kyriakidou O. Diffusion of innovations in service organizations: systematic review and recommendations. Milbank Q. 2004;82(4):581-629.

20. Cook JM, O'Donnell C, Dinnen S, Coyne JC, Ruzek JI, Schnurr PP. Measurement of a model of implementation for health care: toward a testable theory. Implement Sci. 2012;7:59.

21. Canadian Institutes of Health Research. Guide to knowledge translation planning at CIHR: integrated and end-of-grant approaches. https://cihr-irsc.gc.ca/e/documents/kt_Im_ktplan-en.pdf. Published 2012. Accessed Jul 27, 2020.

22. Pinnock H, Barwick M, Carpenter CR, et al; StaRI Group. Standards for Reporting Implementation Studies (StaRI) statement. BMJ. 2017; 356:i6795.

23. Patton MQ. Qualitative Research \& Evaluation Methods. 4th ed. London, UK: Sage Publications; 2014.

24. Saunders B, Sim J, Kingstone T, et al. Saturation in qualitative research: exploring its conceptualization and operationalization. Qual Quant. 2018;52(4):1893-1907.

25. Sandelowski M. Sample size in qualitative research. Res Nurs Health. 1995;18(2):179-183.

26. Braun V, Clarke V. Using thematic analysis in psychology. Qual Res Psychol. 2006;3(2):77-101.

27. Health Canada. MIFEGYMISO (mifepristone and misoprostol tablets) - Updates to Product Monograph and Risk Management Plan. https:// healthycanadians.gc.ca/recall-alert-rappel-avis/hc-sc/2017/65030aeng.php. Published Nov 7, 2017. Accessed Jul 27, 2020.
28. Contraception and Abortion Research Team (CART-GRAC). Canadian Abortion Providers Support (CAPS CPCA). Community of Practice. https://www.caps-cpca.ubc.ca/index.php?title=Main_Page. Accessed Jun 12, 2019.

29. Yanow $S$. It is time to integrate abortion into primary care. Am J Public Health. 2013;103(1):14-16.

30. Grossman D, Goldstone P. Mifepristone by prescription: a dream in the United States but reality in Australia. Contraception. 2015;92(3): 186-189.

31. Dawson AJ, Nicolls R, Bateson D, et al. Medical termination of pregnancy in general practice in Australia: a descriptive-interpretive qualitative study. Reprod Health. 2017;14(1):39.

32. Raymond EG, Grimes DA. The comparative safety of legal induced abortion and childbirth in the United States. Obstet Gynecol. 2012; 119(2 Pt 1):215-219.

33. Joseph KS, Liu S, Rouleau J, et al. Severe maternal morbidity in Canada, 2003 to 2007: surveillance using routine hospitalization data and ICD-10CA codes. J Obstet Gynaecol Can. 2010;32(9):837-846.

34. Schummers L, Norman WV. Abortion services in Canada: access and safety. CMAJ. 2019;191(19):E517-E518.

35. Warden S, Genkin I, Hum S, Dunn S. Outcomes during early implementation of mifepristone-buccal misoprostol abortions up to 63 days of gestation in a Canadian clinical setting. J Obstet Gynaecol Can. 2019;41(5):647-652.

36. Raymond EG, Shannon C, Weaver MA, Winikoff B. First-trimester medical abortion with mifepristone $200 \mathrm{mg}$ and misoprostol: a systematic review. Contraception. 2013;87(1):26-37.

37. Gold M, Chong E. If we can do it for misoprostol, why not for mifepristone? The case for taking mifepristone out of the office in medical abortion. Contraception. 2015;92(3):194-196.

38. Foster AM, Jackson CB, LaRoche KJ, Simmonds K, Taylor D. From qualified physician to licensed health care professional: the time has come to change mifepristone's label. Contraception. 2015;92(3): 200-202. 